Meta

Journal des traducteurs

Translators' Journal

\title{
Analysing Literary Discourse: Implications for Literary Translation
}

\section{Kazem Lotfipour-Saedi}

Volume 37, numéro 2, juin 1992

URI : https://id.erudit.org/iderudit/004016ar

DOI : https://doi.org/10.7202/004016ar

Aller au sommaire du numéro

Éditeur(s)

Les Presses de l'Université de Montréal

ISSN

0026-0452 (imprimé)

1492-1421 (numérique)

Découvrir la revue

Citer cet article

Lotfipour-Saedi, K. (1992). Analysing Literary Discourse: Implications for Literary Translation. Meta, 37(2), 193-203. https://doi.org/10.7202/004016ar
Résumé de l'article

On étudie la notion d'équivalent en traduction dans le discours littéraire. La littérature se distingue de la non-littérature par l'effet particulier qu'elle produit chez le lecteur. C'est cet effet que l'on tente de décrire à l'aide des stratégies spécifiques au discours et au texte littéraire. On examine enfin l'utilisation de ces stratégies et les répercussions sur la traduisibilité des textes littéraires. 


\title{
ANALYSING LITERARY DISCOURSE: IMPLICATIONS FOR LITERARY TRANSLATION
}

K. LOTFIPOUR-SAEDI

University of Tabriz, Tabriz, Iran

\begin{abstract}
Résumé
On étudie la notion d'équivalent en traduction dans le discours littéraire. La littérature se distingue de la non-littérature par l'effet particulier qu'elle produit chez le lecteur. C'est cet effet que l'on tente de décrire à l'aide des stratégies spécifiques au discours et au texte littéraire. On examine enfin l'utilisation de ces stratégies et les répercussions sur la traduisibilité des textes littéraires.
\end{abstract}

\begin{abstract}
This paper will attempt to look at the notion of translation equivalence in literary discourse. Literature is usually distinguished from non-literature in terms of the special effect it creates on the reader. The paper will try to characterize this "special effect" in terms of special discoursal and textual strategies employed in literary text. It will then examine ways of rendering such strategies in the translation process drawing implications for the issue of translatability in literature.
\end{abstract}

\section{INTRODUCTION}

This paper will first define the notion of translation equivalence within the framework of modern trends in language studies. It will then attempt to characterize the notion of literary function or "literary effect" in terms of the way language resources (sound, grammar, meaning) are utilized by the discourse producer for literary purposes. In the last section, the issue of "translation equivalence" in literature and whether/how the same literary effect as the one intended by the original author can be preserved in the translation process will be discussed for the purpose of drawing implications for the literary translation.

\section{THE NOTION OF TRANSLATION EQUIVALENCE}

Translation is normally defined as the process of replacing source language (SL) textual materials by equivalent target language (TL) textual materials (Catford 1965). Attempts have been made to define the nature of translation equivalence (TE) within the framework of different approaches to the study of language (Catford 1965, Nida 1964, Newmark 1981). We have used the comprehensive discourse framework to characterize the nature and components of TE. This characterization has already been elaborated upon in detail elsewhere ( $c f$. Lotfipour-Saedi 1990 and forthcoming). Here, we shall only make a very brief reference to these components.

According to our formulation of the theory and principles of translation, seven components should be taken care of in any attempt to define the nature of translation 
equivalence: vocabulary, structure, texture, degree of indirection, language variety, cognitive effect and aesthetic effect. Anyone involved in translation, whether in the practical translation process, or in the evaluation of the translated texts, or in formulating theory of translation, should take care of all these seven components. Before we present a brief account of these components, two points should be clarified. The components listed above should be viewed not as isolated entities but rather as factors which are closely interrelated. They are sub-systems of choices ( $c f$. Halliday 1985) within the overall language system and the communicatively (co-textually, contextually and interpersonally) motivated choices from each of these sub-systems contribute to the materialization of the "text;" and the text, rather than carrying the meaning, as traditionally maintained, acts as a mediator to set the receiver-discourse process in operation through which a meaning (possibly compatible with the one intended by the sender) may be arrived at. Thus any handling of these components in isolation from one another and any mis-handling of these would render a change in the "textuality" of the text and the meaning mediated by it. The second point of clarification concerns the verb take care of used in our sentence above which insisted that all the seven components should be taken care of in any attempt to characterize the nature of TE. Different languages may vary in their structure, i.e. the type of textual resources they employ for communicating a certain message. One language may opt for one set of textual sub-systems while another language may choose a different set of sub-systems for the materialization of a text with identical communicative motivations. Thus the translator cannot be expected to try to replace all the SL text sub-systems by those TL text sub-systems which are traditionally thought to be parallel to those in SL. For example, he cannot always replace the SL tense, aspect, mood, word-form, phrase, etc. by the parallel TL tense, aspect, mood, word-form, phrase, etc. respectively. Such a rendition which has usually been referred to as structure-forstructure translation cannot always be acceptable and may sometimes lead to TL texts carrying SL values rather than TL ones. What a translator should rather do is to operate within the overall discourse framework trying to convey the communicative values of the SL author by employing TL textual strategies which are equivalent in their discoursal function to those in SL. To attain such an objective, he should not neglect any of the above-mentioned components of TE. These components will be briefly explained below:

1) Vocabulary: In determining the TL equivalents of the SL vocabulary items, the translator should firstly endeavour to take care of all the shades of meaning reflected in the SL lexical item including denotative, connotative, stylistic, collocative, contrastive, reflected, implicative and figurative shades; secondly he should know that, due to the possible differences between language systems the relationship between the lexical "forms" and their meaning "substance" may vary across languages and different languages may employ different strategies for the lexicalization of the same meaning. What the translator should, thus, consider is not the SL word forms but rather the "meaning substance" they contract within the SL discourse process; he should then take this "meaning substance" and see how he can lexicalize it within the TL lexical structure.

2) Structure: As languages may differ in the number of their structural/grammatical elements and their communicative value, structure-for-structure translation, i.e. replacing an SL structural element by what is normally considered as its parallel structure in TL, should be avoided. Structure is a linguistic device serving communicative goals. In his attempt to replace the SL structure by its TL equivalent structure, the translator should rather take the communicative goal mediated by the structure at hand as his guiding principle and see how he can present that goal in TL. 
Due to the arbitrary nature of the form-function relationship in languages the communicative value of two cross-linguistically parallel structures may vary making structure-for-structure rendition doomed to failure.

3) Texture: Under this component we have included the following textual features:

a) Thematization strategies: what the writer chooses to stand as the theme (cf. Halliday 1985) of the sentences of his text.

b) Textual schematic structure: the overall structure or macro-structure of the text.

c) Textual cohesion: the type and number of cohesive devices employed in the text which contribute to the degree of cohesiveness of the text ( $c f$. Halliday and Hasan 1976, Halliday 1985).

d) Paralanguage: the paralinguistic elements used in the text, including the prosodic features such as intonation, stress patterns (in spoken text) and typographic elements such as underlining, italicizing (in written text) which contribute to the texture of a text by creating contrasts between elements across the text.

All the above textual features can be seen as textual strategies employed by the writer/speaker; and any variation in them can be argued to have effects on the reader discourse comprehension process and the message to be negotiated.

4) Degree of indirection: By this we mean the nature of relationship between form and function, i.e. how directly or indirectly a language form can be seen to relate to the discoursal function it is intended to perform. The degree of indirection is argued to be a function of textual features such as mood, transitivity; and it would be affected by any change in such features.

5) Language variety: Features reflecting various language varieties (social, interpersonal, registerial, etc.) should be preserved in the translation process. This does not, however, mean that feature-for-feature translation across languages can always be acceptable because a special variety which may be represented by, for example, tense or aspect in one language may be represented by quite different structural features in another language. The translator should thus attempt to preserve the SL variety in TL, bearing in mind such textualization differences across languages.

6) Cognitive effect: By this we mean features such as the degree of "comprehensibility" and "recallability" of a text which should be preserved in the translation process.

7) Aesthetic effect: By aesthetic effect we mean the special effect which a literature-text is argued to have on the reader. This "effect" is the theme of the present paper and will be examined in more detail in section 3 below. The translator should also take care of the aesthetic effect in his attempt to establish TE. All the above components of TE have been discussed in full detail elsewhere (see Lotfipour-Saedi 1990 and forthcoming). We have also discussed whether all these TE components can be equally taken care of in translating between all languages the implications of the answer to this question for the issue of translatability, and the appropriate translation-strategies one may employ in connection to that answer and the implications thereof.

\section{ANALYSING LITERARY DISCOURSE}

In order to be able to determine the nature of TE in literature, we should first try to characterize the nature of literary discourse and see what it is that distinguishes literature from non-literature. Some stylisticians have defined certain aspects of the difference between literature and non-literature in terms of special patterns contained in literature 
(see, e.g. Widdowson 1975, Cummings and Simmons 1983). They have argued that these patterns (phonological, structural, semantic and graphological), which cannot be accounted for by ordinary linguistic rules, and which are imposed upon ordinary language patterns, bestow upon them a special value which can be referred to as their literary value or literary effect. But looking at the distinction between literature and nonliterature in terms of formal features would certainly meet drawbacks. A literary text assumes its literary value not merely due to such patterns, and the presence of such patterns is not a necessary and sufficient condition to create literature. We can find instances of literary text without any overt special patterns and there may be texts abounding in special phonological, structural and semantic patterns without displaying any literary value. Literature can be distinguished from non-literature mainly from the viewpoint of its function, the literary effect:

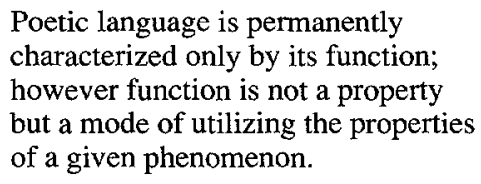

\section{Mukarovsky (1977)}

But such a function, or the literary effect is not an inherent property for literature. Literature assumes its literary status and achieves its special literary effect in the light of a special mode of utilizing the properties of language or as a result of a special patterning of language patterns (Hasan 1985). The special patterns employed in literature which are usually referred to as foregrounding (cf. Garvin 1964), are normally distinguished from other "prominent" patterns used in non-literary texts. Mukarovsky attributes two characteristics to foregrounding and believes that for foregrounding to have maximum effect it should be firstly "relational" and secondly "consistent and systematic". Leech (1970) also introduces the notion of cohesion to this effect and maintains that foregrounding devices should be cohesively related to one another in order to exert a more powerful effect on the text. To give an example, look at the following verse from Tennyson's In Mermoriam;

He is not here; but far away

The noise of life begins again,

And ghastly thro' the drizzling rain

On the bald street breaks the blank day

Here the function of the foregrounding devices (i.e. the monosyllabic structure of the words in the last line and the alliterative pattern they form) is consistent with the theme of the verse; in other words, they reinforce the semantic load of the lexical items carrying them, which is the desolation experienced by the poet ${ }^{1}$. But in reading the following texts which are merely pieces of advertisements without any literary value:

\section{Kwick kopy (presenting the text: Quick Copy)}

JC $4 \mathrm{U}$ (presenting the text: Jesus Christ for you)

the reader would certainly be attracted and affected by the "prominence" of the elements contained in them; but he can not perceive the relationship between such an effect and the meaning (theme) underlying them. Classifying the uses of "symbols" in language into "referential" and "evocative symbolism" on the basis of the way in which "linguistic symbols" are used, Pollock (1965) defines the former as using language to direct the attention of readers towards certain referents and to arouse attitudes or overt activity in 
connection with them (as in non-literary use of language) and the latter as using language to evoke experience (as in literature). He says:

The difference between symbols used as propaganda and symbols used as literature is found... not on the form of the utterance, but on the intention.

Pollock (1965: 196)

Hasan (1985) also sees the significance of foregrounding residing not on its formal characteristics but on its "consistency" and says that there are two aspects to this consistency: the stability of its semantic direction and the stability of its textual location. By the former she means "that the various foregrounding patterns point toward the same general kind of meaning" and by the latter she means "that the significant patterns of foregrounding have a tendency to occur at a textually important point" (Hasan 1985: 95).

We choose to use the term literary coherence to refer to these complementary conditions of foregrounding devices in literature, i.e. the "cohesiveness", "systematic character" and consistency of such devices, the fact that they contribute to the "semantic drift" (Butt 1984) of the text, and that they are "motivated" by the vision of the text (Halliday 1971); and we define it as the consistency between the "theme" of the text and the function or the discoursal effect of the foregrounding devices presented in it. In the same vein, we define the comprehension of literary discourse or rather the appreciation by the reader of such a coherence. In other words, in reading a piece of poetry, the reader comes across a foregrounding device, and having perceived the theme of the text, recognizes how that device contributes to the actual crystalization of the message; and it is through a recognition of the literary coherence or rather the comprehension of the literary text that he experiences a "literary" or "aesthetic" effect.

According to our characterization of writer-reader interactive discourse processes (cf. Lotfipour-Saedi 1982), the writer-discourse process consists of a set of discoursal strategies each oriented towards one of the factors involved in the discourse production process. The text, as the linear presentation of the discourse, is seen to consist of a set of hierarchically organized theme-rheme units, each presenting a discourse strategy. The actual surface realization of each potential theme-rheme unit may vary along three dimensions of rank (sentence, clause, group or word), mode (segmental, suprasegmental including typographics, intonation, etc.) and level (the depth of the embeddedness in the textual hierarchy); and this variation is determined by a set of textualization factors.

Thus we see the written text as embodiment of a set of discoursal and textual strategies, each of which is oriented towards the respective factors involved in the discourse production and textualization processes. What the reader receives in reading a text and what affects the reader-comprehension process is not only the writer discoursal strategies but also his textual strategies. In other words, what is said is as much important in the writer-reader interaction process as the way it is said.

\section{DISCOURSAL AND TEXTUAL STRATEGIES IN LITERATURE}

The special patterning of language patterns in literature-text or the foregrounding devices can be viewed as "special" discoursal and textual strategies.

In other words, literature-text is different from non-literature in terms of the nature of both discoursal and textual strategies employed in it; and the literary effect or the aesthetic effect of literature can be argued to be a function of both of these special strategies.

In other words, if the writer-reader interaction in non-literature can be depicted in diagram (1) below: 


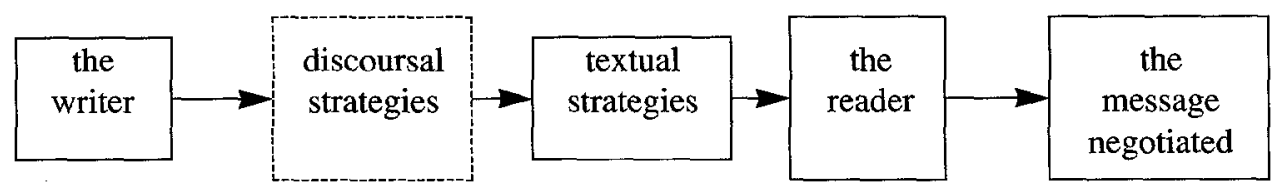

such an interaction in literature may be illustrated in diagram (2) as follows:

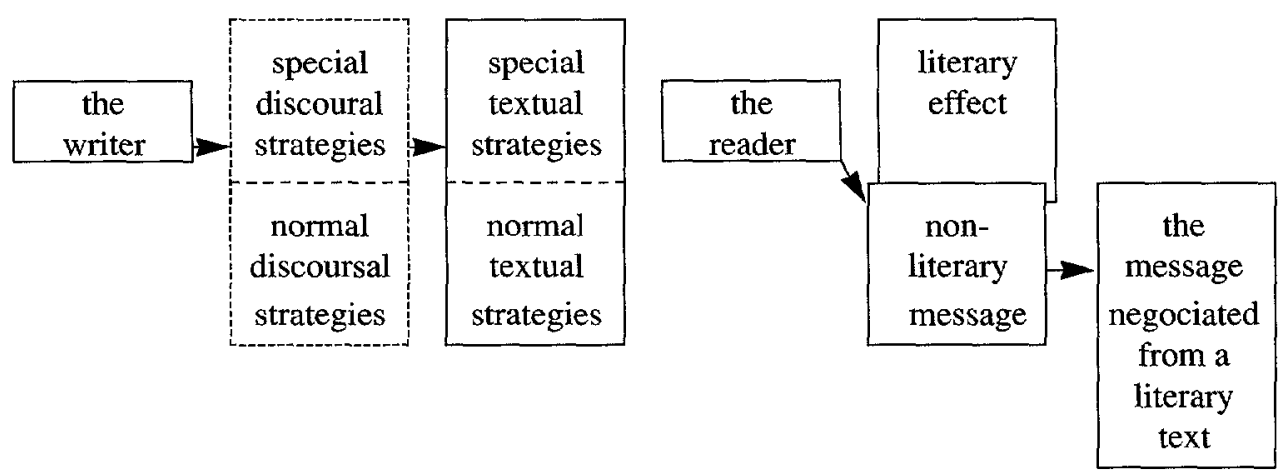

As this diagram would indicate, the special discoursal and textual strategies employed in literature are strategies which are superimposed on normal strategies and add extra dimensions to the meaning to be negotiated, which are usually referred to as aesthetic or literary effect.

By discoursal strategies, as a whole, we mean the pre-textual decisions made by the discourse producer and by textual strategies we mean the way such decisions are presented to the reader. As we noted above, the textual strategies or the way something is said have certain effects on the message. But the degree of the importance of these strategies may vary according to the text-type and this variation can be viewed as a parameter in distinguishing literature from non-literature: i.e. the more the importance of the textualization strategies employed in a text, the higher the probability for it to be considered as a literary text.

Thus the distinction between literature text and non-literature text on the basis of this parameter is a matter of scale and degrees rather than being a clear-cut dichotomy. In other words, some texts are more literary than others, i.e. the way the message is expressed assumes more importance in some texts than others. Indeed, to our view, it is perhaps due to the higher value and importance of the textualization strategies in literature that the different categories of discoursal strategies to be discussed below will have more inclination to be seen as textual strategies than discoursal strategies. But since we view them as pre-textual decisions and since each can have different textual realizations under varying textual factors, we classify them under discoursal strategies.

\section{LITERARY DISCOURSAL STRATEGIES}

The discoursal strategies, as we noted before, are pre-textual decisions made within the framework of the dominating discoursal factors.

Such strategies in literature, as the diagram (2) would indicate do not replace those in non-literature, but rather add new dimensions to the ordinary (non-literary) discoursal strategies.

Among the literary discoursal strategies we can name indirection, indeterminacy and defamiliarization. We shall elaborate on each of these below; but their 
exemplification will not be possible at the discoursal level, and any ambiguities regarding their nature will certainly be clarified when the literary textual strategies are presented.

\section{INDIRECTION}

Indirection, and indeed all the other literary discoursal strategies, are also found in non-literature, but, as we discussed above, they assume literary character and change into foregrounding devices rather than being purely prominent by way of their being thematically motivated. In non-literature, indirection is a function of any violation of the conventional correlation between form and function. For example a statement which is conventionally correlated with the function of giving information may, under certain discoursal factors, be used for asking somebody to do something. The literary discourse producer mostly attempts to achieve his communicative goals through indirect strategies. For example, Shakespeare, for the purpose of conveying a certain message, say, hesitation rather than putting it directly in a sentence or two, uses the framework of a play called Hamlet. The whole play can be viewed as a macro-literary discoursal strategy presenting a large number of micro-strategies, and indirection is also employed at these micro-levels. It is through this indirection and of course, other types of special discoursal strategies employed in this play that the author achieves special effect which may be referred to as literary effect. Thus a message, which in non-literature can be conveyed directly by a simple sentence, in literature may be presented within the framework of an anecdote and such frameworks we take as indirection discoursal strategies at a macrolevel.

\section{INDETERMINACY}

By indeterminacy as a discoursal strategy we mean the indeterminacy of the discourse producer's intended message to the discourse comprehender. This is, of course, a feature which characterizes any type of verbal interaction; and according to new trends in linguistics, especially the ethnomethodologists (cf. Garfinkle 1967, Circourel 1973) the meaning intended by a discourse producer in a text may not necessarily be the one which a discourse comprehender may arrive at in reading / listening to that text, as the text is only one of the factors involved in meaning negotiation process, the others being the context, reader factors etc. Indeed, it is this indeterminate nature of the message "mediated" by "texts" which bestows upon "language" its so highly boasted feature, i.e. "creativity", without which natural language would have changed into a set of rigid formulae which could be mastered by any animal without requiring a "thinking" mind. The indeterminacy in literary discourse assumes higher and special proportions which distinguish it from non-literature.

\section{DEHABITUALIZATION}

By dehabitualization, we mean the strategies which literature employs to deeply involve the addressee in interaction with the text and to force him to go beyond a mere involuntary perceiving of the text to the voluntary and active processing of the presented discourse. Literature as an art, attains this by employing unique and, in some senses, queer modes of presentation to make "things" look unfamiliar:

Habitualization devours objects, clothes, furniture, one's wife and the fear of war.

If all the complex lives of many people go on unconsciously, then such lives are as if they had never been!

Art exists to help us recover the sensation of life; it exists to make us feel things, to make the stone Stony. The end of art is to give a sensation of the object as seen, not as recognized. 
These special discoursal strategies achieve their special literary effect by adding an "unfamiliarity" dimension to the message and thus prolonging the act of perception:

The technique of art is to make things unfamiliar, to make forms obscure, so as to increase the difficulty and the duration of perception.

Shklovsky 1965

The act of perception itself, its duration and degree of difficulty may be considered as part of the literary effect:

The act of perception in art is an end in itself and must be prolonged. In art, it is our experience of the process of construction that counts, not the finished product.

Shklovsky 1965

\section{LITERARY TEXTUAL STRATEGIES}

As we noted above, the discoursal strategies are pre-textual decisions and thus they should be textually presented. We used textual strategies to refer to different modes of this presentation; and we argued that the textual strategies (i.e. the way something is said) are as important in the meaning negotiation process as the discoursal strategies (i.e. what is said). The special textual strategies employed in literature, or the literary textual strategies assume more importance and indeed the degree of the importance of the textual strategies was considered as a parameter in distinguishing literature from non-literature.

In other words, in literature, especially in highly literary text, the textual strategies assume so much importance that the border between them and their underlying discoursal strategies becomes fuzzy and very hard to recognize, i.e. textual strategies assume the role of discoursal strategies and the way of presenting plays a crucial and determining role in the meaning negotiation process.

Textual strategies, whether literary or non-literary, are in fact the choices the language user makes from among the linguistic resources available to him and any choice, rather than being "free" in variation, is meaning - and function-related and as Halliday would note language is the way it is because of the function it is required to perform (cf. Halliday 1970). But in the case of literary textual strategies the formfunction relationship or rather the relationship between the linguistic choices made and the motivation for such choices is of special nature. They are less conventional and more idiosyncratic to the discourse producer requiring a lot of thinking and imagination on the part of the discourse receiver for their decoding, i.e. for establishing the relationship between the choices made and their underlying motivation. It is, indeed, this special nature of the literary textual strategies which contributes to their importance in the meaning to be negotiated, promotes their discoursal function and, as a result, makes them indispensable to the text.

To exemplify the literary textual strategies we may name the following: rhythm, metric patterns, assonance, alliteration, structural parallelism, metaphor, simile, irony, etc. On the basis of the tripartite language compartments (sound / meaning/grammar) these strategies are normally classified into phonological, semantic and structural (cf. Widdowson 1975 and Cummings and Simmons 1983). The question which is now raised relates to the relationship between the textual strategies and their underlying discoursal strategies. In other words what literary discoursal strategy a special literary textual strategy represents? The answer to this question itself illuminates the nature of the literary textual strategies. As in the case of the relationship between non-literary discoursal and textual strategies, where there is no one-to-one relationship between, so- 
to-speak, form and function, there can be no established one-to-one relationship between a literary discoursal strategy and a special mode of presentation. For instance, indirection as a literary discoursal strategy may on surface be presented by different textual strategies such as metaphor, rhythm, metric patterns, etc. This volatility of relationship between form and function indeed reaches its climax in highly literary texts adding to the indeterminacy of the message and increasing the reader options in the formulation of the message to be negotiated. This feature demonstrates again the importance of the textual strategies and the disappearing of the border-line between discoursal and textual strategies in terms of their function in literature.

\section{ALL THESE STRATEGIES EMPLOYED BY THE LITERARY PRODUCER HAVE SPECIAL EFFECTS ON THE READER:}

a) Through their uniqueness and novelty (as, for example, in the case of the textual deviations and poetic diction employed in literature) they create a denaturalizing and defamiliarizing effect on the reader and force him "to read" what he receives and to attend to it;

b) through the indeterminate nature of these strategies (as, for example, in the case of the semantic patterns such as metaphors), they launch the reader's imagination into operation adding to the imaginative nature of the meaning to be negotiated;

c) through the highly indirect mode of communicating meaning in literature, the reader, apart from being forced to operate his imagination for establishing a meaning (as in the case of $b$ above) is allowed more options for formulating a message from the text; and the more the reader options in the text-reader interaction process, the higher his dynamic and active involvement in the meaning negotiation process and the deeper the cognitive effect of the text on the reader.

d) through the use of the semantic strategies such as symbolism (as a textual strategy), some literary textual strategies open up quite unprecedented and novel universes of discourse for the reader by allowing the attributes of two lexical items to interact in an indirect manner activating local discourse processes which lead to the negotiation of imaginative and novel meaning.

This makes it possible for the literary producer to express what is unexpressable in ordinary language.

The overall effect of all these strategies is to involve the reader in a prolonged voluntary, dynamic, imaginative and goal-oriented search for a meaning:

The act of perception in art is an end in itself and must be prolonged. In art, it is our experience of the process of construction that counts, not the finished product.

(Shklovsky 1965)

This overall effect and the sense of achievement experienced by the reader, when a hard-sought-for meaning materializes, may be argued to be the literary or aesthetic effect of the literary text.

\section{LITERATURE AND TRANSLATION EQUIVALENCE}

In the above two sections we first defined TE in terms of a set of conditions and then tried to distinguish literature from non-literature in terms of the special literary effect which was argued to be a function of special discoursal and textual strategies employed by the literary producer apart from non-literary discoursal and textual strategies. We also 
presented some speculations on the literary/aesthetic effect of these strategies. We now examine the issue of translation of literature-text as characterized above.

As we discussed above, the border-line between function and form (i.e. what is said and the way it is said) almost disappears in literature and the way something is said or the textualization strategies assume utmost importance in the materialization of a message and any change in the way of saying would certainly lead to a change in the meaning to be negotiated.

Thus in the translation process, the SL textual strategies can never be ignored. In other words, in translating literature-text, the translator's task is not only to encode the original author's message in TL, but also to preserve the author's way of saying it, i.e. his textual strategies, and try to replicate them, if possible in TL. The questions which are raised now are on how / if they can be exactly rendered in TL. Any possible answer to such questions are examined below:

a) SL textual strategies i.e. special patterns are exactly recreated in TL, e.g. alliteration for alliteration, metaphor for metaphor, rhyming for rhyming...

This can be easily disproved on the basis of the difference between language systems and the relevant socio-cultural values.

b) SL literary text may be translated into a text which can be claimed to be literary in terms of containing special patterns i.e. translate SL literary text into a text with special patterns which do not necessarily correlate with those in SL, e.g. translating poetry into a text with rhyming patterns or using special diction in TL etc. this cannot be acceptable because one cannot merely include a few special patterns in his rendering to make it equivalent to SL in terms of the literary values; the lexical carrier of the literary patterns in SL and the relationship which is established between these two are also important; and this cannot be taken care of for the reason discussed in (a) above.

\section{SOME RECOMMENDATIONS ON APPROPRIATE TRANSLATION STRATEGIES IN LITERATURE}

Having characterized the literature text in terms of the special discoursal and textual strategies super-imposed upon ordinary discoursal and textual strategies, and having noted the special status the textual strategies (way of saying what one wants to say) assume in literature, the obvious and indispensable implication for the translation of literature is that what is important for the translator in his attempts to establish translation equivalence is not what the original author wants to say but also the way he says what he wants to say. The principle, as we noted before, also applies to the translation of nonliterature. But the textual strategies assume more importance in literature and as a result their neglect on the part of the translator becomes more calamitous in literature accordingly: i.e. the more literary a text, the more important the textual strategies employed by it and the more calamitous their neglect, by the translator, to the original author's message.

But due to the arbitrary nature of the relationship between language forms and language functions, and because of the structuralist principle that every language is a unique system and as such the textual devices used for an identical communicative purpose may vary across languages, the task of maintaining functionally "equivalent" ways of saying or textual strategies in translating literary texts seems extremely difficult if not impossible.

A very general guideline we can offer in the light of the above characterization towards a better translation of literature-text is that the translator should preserve the SL way of saying or rather the special patterning of language patterns (cf. Hasan 1985) in translating such texts. This, however, does not mean he should translate pattern-for- 
pattern (e.g. rhyming-for-rhyming, alliteration-for-alliteration, symbol-for-symbol), because, as noted above, due to differences in linguistic resources employed by languages for an identical communicative purpose, such a rendition may lead to quite unacceptable TE's. What he should rather do is to examine the value of the underlying discourse strategy of the SL special textual strategies and then try to see what TL special textual strategies he can employ for conveying the same value. For example he may opt for replacing a special pattern from the SL sound system by a special pattern from the TL grammatical system. But what should be borne in mind in making such decisions is that the TL special textual strategies should be equivalent to the SL ones in terms of their degree of indirection, indeterminacy and denaturalizing effect.

More specific guidelines will be speculated upon on the translation of different literary genres in our forthcoming papers.

Note

1. I owe this example and its analysis to Widdowson (1975).

\section{BIBLIOGRAPHY}

BUTT, D.G. (1984): "To be Without a Description of to be. The Relationship between Theme and Lexicogrammar in the Poetry of Wallace Stevens", unpublished Ph.D. thesis, University of Macquarie.

CATFORD, J.C. (1965): A Linguistic Theory of Translation, London, Oxford University Press.

CICOUREL, A. (1973): Cognitive Sociology, Penguin.

CUMMINGS, M. and R. SIMMONS (1983): The Language of Literature: Intraduction to the Study of Literature, Pergamon Press.

GARFINKEL, H. (1967): Studies in Ethnomethodology, Englewood Cliffs, N.J., Prentice-Hall.

GARVIN, P. (1964): A Prague School Reader on Esthetics, Literary Structure and Style, Washington, Georgetown University Press.

HALLIDAY, M.A.K. (1970): Language Structure and Language Function, Lyons, New Horizons in Linguistics, Penguin, pp. 140-165.

HALLIDAY, M.A.K (1971): "Linguistic Function and Literary Style: an Inquiry in to the Language of William Golding's The Inheritors', Chatmans, H. ed.

HALLIDAY, M.A.K. (1971): Literary Style: a symposium, New York, 1975, OUP.

HALLIDAY, M.A.K. (1985): An Introduction to Functional Grammar, Amolds.

HALLIDAY, M.A.K. and R. HASAN (1979): Cohesion in English, London, Longmans.

HASAN, R. (1985): Linguistics, Language Verbal Art, Victoria, Deakin University Press.

LEECH, G.N. (1970): "This Bread I Break - Language \& Interpretation", Freeman, D.C. ed., Linguistic and Literary Style, New York, Holt, Rinehart and Winston Inc.

LOTFIPOUR-SAEDI, K. (1982): Applying an Analysis of the Writer-Reader Discourse Processes to a Pedagogy of Reading, unpublished Ph.D. thesis, University of Lancaster, U.K.

LOTFIPOUR-SAEDI, K. (1990): "Discourse Analysis and the Problem of Translation Equivalence", Meta 35-2.

LOTFIPOUR-SAEDI, K. (forthcoming): An Introduction to the Theory of Translation, Iran University Press.

MUKAROVSKY, J. (1977): The Word and Verbal Art, transl. J. Burbank and P. Steiner, New York, Yale University Press.

NIDA, E.A. (1964): Towards a Science of Translating, Brill, Leiden.

NEWMARK, P.: Approaches to Translation, Pergamon Press, Oxford.

POLLOCK, T.C. (1965): The Nature of Literature. Its Relation to Science, Language and Human Experience, New York, Gordian Press.

SHKLOVSKY, V. (1965): Russian Formalist Criticism: Four Essays Lincoln, L.T. Lemon and M. Reis, Nebraska University Press.

WIDDOWSON, H.G. (1975): Stylistics and the Teaching of Literature, London, Longmans, reprinted in 1984. 